\title{
De la causa, el principio y el uno, de Giordano Bruno
}

\author{
Traducción, introducción y nOtas de Miguel Á. Granada (2018).
}

Madrid: Tecnos, 408 páginas.

\section{Agustín Gabriel Bianchi}

Universidad Nacional de General Sarmiento, Argentina

Luego de la publicación del diálogo La cena de las cenizas (Tecnos, 2015), De la causa, el principio y el uno (Tecnos, 2018) representa la segunda obra de Giordano Bruno editada por Tecnos en su colección de Clásicos del Pensamiento. Ambas obras, traducidas al castellano por Miguel Ángel Granada-y a las que se sumará Del infinito: el universo y los mundos (Tecnos, 2019)-, pertenecen a los diálogos filosóficos en lengua italiana que Giordano Bruno publica en Inglaterra.

De la causa, el principio y el uno es la obra más difundida y discutida del filósofo italiano. Publicada en Londres en el año 1584 junto con La cena de le ceneri, De l'infinito universo et mondi y Spaccio de la bestia trionfante, forma parte del conjunto de obras conocido como dialoghi italiani, completado un año más tarde con la publicación de La cabala del cavallo Pegaseo y De gli eroici furori.

El diálogo que nos ocupa, luego de la epístola proemial, está dividido en cinco partes que, juntas, conforman la exposición más completa de la metafísica de Bruno. A lo largo del tratado De la causa, Bruno introduce los fundamentos metafísicos del universo infinito que postula a partir de la radicalización de la cosmología heliocéntrica de Copérnico, cosmología que defiende en La cena de le ceneri. En efecto, la conexión entre ambos diálogos queda ratificada en la primera parte del De la causa, que resulta ser una apología de La cena (en ese diálogo se narra la disputa de Bruno con dos doctores oxonienses en la cena del Miércoles de Ceniza, circunstancia que da el nombre a la obra). La segunda parte del De la causa está dedicada al tratamiento de la causa, tanto eficiente, como formal y final. La tercera y cuarta parte tratan el principio formal y, sobre todo, la materia. Por último, la quinta parte está dedicada al uno, donde convergen materia y forma, acto y potencia, llegando a su máxima expresión el monismo ontológico de Bruno.

Bruno aborda la estructura ontológica del universo por medio de la doctrina aristotélica de las cuatro causas: eficiente y final, tratados propiamente como causas por Bruno (debido a que causa eficiente y final son causas extrínsecas a sus efectos); formal y material, principios en la ontología bruniana (principios porque forma y materia son causas intrínsecas a sus efectos). De estas causas, ocupa un lugar especial en la ontología del nolano el tratamiento de la materia, en efecto, el "discurso sobre ella tiene en gran medida el carácter de una reivindicación" (p. XLIII). Esta reivindicación está dirigida a la tradición aristotélica, platónica y judeocristiana, que veían a la materia como mera receptora de las formas; esencialmente pasiva. En contraposición a esta perspectiva, en la filosofía de Bruno la materia no es un sustrato informe; no es "casi nada" (prope nihil), sino fuente de todas las formas (p. LII). Aún más, "ella [la materia], que explica lo que tiene implicado, es quien debe ser llamada cosa divina, óptima progenitora, engendradora y madre de las cosas naturales, incluso la naturaleza toda en sustancia" (pp. 212-213).

La traducción se encuentra a cargo de Miguel Ángel Granada, profesor de Historia de la Filosofía del Renacimiento en la Universidad de Barcelona. Granada realizó artículos especializados sobre autores como Erasmo de Rotterdam, Maquiavelo, Bernardino Telesio, Francis Bacon, Tomasso Campanella y Giordano Bruno. Ha traducido al castellano obras de todos los pensadores mencionados. Con respecto a Giordano Bruno, Granada es autor de dos libros que recorren distintos ejes de su pensamiento (Giordano Bruno. Universo infinito, unión con Dios, perfección del hombre, Barcelona, 2002; La reivindicación de la Filosofía en Giordano Bruno, Barcelona, 2005) y colaboró a su vez en la edición crítica de la obra de Bruno publicada por Les Belles Lettres (París). Es actualmente una de las voces más autorizadas sobre la filosofía bruniana y la revolución científica de los siglos XVI y XVII.

Esta traducción, además de estar a cargo de un especialista en la Filosofía del Renacimiento como lo es el profesor Granada, recoge al margen la paginación de la edición crítica del texto original italiano de BOEUC 
(Les Belles Lettres: Giordano Bruno, Oeuvres complètes, vol. III, De la cause, du principe et de l'un, París, 1996), edición bilingüe francés-italiano de la obra del nolano. Este valioso recurso permite comparar la traducción de Granada con el texto original.

Por su parte, el texto introductorio que precede a la traducción del diálogo italiano constituye un importante estudio que perfila los principales problemas que tratará la obra. Tal estudio se encuentra dividido en seis apartados: 1. La defensa de La cena en Causa I: reivindicación de la filosofía frente al pedantismo. 2. El conocimiento posible de Dios. De Dios causa transitiva a Dios causa inmanente. 3. Principios y causas: causas eficiente y final; principio formal. 4. La materia. 5. Coincidencia de materia y forma en la unidad de la sustancia infinita. 6. Recepción del De la causa en la filosofía europea. Especialmente interesantes son los apartados dedicados a la materia y a la recepción del De la causa en la filosofía europea. La decisión de dedicarle un apartado independiente a la materia se encuentra plenamente justificado por ser una de las cuestiones más originales del diálogo. En este sentido, Granada examina las distintas perspectivas desde las cuales el autor del De la causa presenta la materia y el valor de este concepto como fundamento de la filosofía natural y metafísica propuestas por Bruno.

En el último apartado de la introducción, Granada realiza un recorrido a través de la historia del pensamiento posterior a la muerte de Giordano Bruno para mostrar la recepción de la obra traducida en este volumen. El itinerario va desde la valoración negativa de Marin Mersenne hasta la valoración positiva de Arthur Schopenhauer, pasando por un posible pero incierto- conocimiento de esta obra por parte de Baruch Spinoza y la relación entre ambos autores -Bruno y Spinoza- que realiza Pierre Bayle en su Dictionnaire historique et critique. Otros autores que aparecen en esta historia de la recepción del De la causa son Diderot, Leibniz, Schelling, Hegel y Jacobi; autor este último de "la primera traducción que se imprimiría del De la causa (y aun de una obra de Bruno)" (p. LXXI). Este breve itinerario de la recepción del De la causa de Bruno resulta de suma utilidad para el estudio de las proyecciones del pensamiento bruniano en la temprana y tardía Modernidad.

Sobre la recepción de los estudios brunianos en general y el De la causa en particular por parte de la historiografía contemporánea encontramos una extensa nota al pie hacia el final de la introducción preliminar. Allí se nos dice que el De la causa fue desplazado a un segundo plano a partir de la monumental monografía de Frances Yates Giordano Bruno and the Hermetic
Tradition (1964), luego de haber estado en la posición central de los estudios sobre el nolano. Afortunadamente, según Granada, esta apreciación, sumado a otros errores introducidos por esta monografía, han comenzado a subsanarse en los últimos treinta años a partir de estudios que "han devuelto a De la causa, principio e uno su lugar de primerísimo plano en la "nolana filosofía»" (nota al pie 141, p. LXXIX). La traducción y el estudio preliminar de Granada forman parte de estas investigaciones que procuran otorgar al De la causa su importancia dentro de las obras de Bruno en particular, y de la filosofía renacentista en general.

Encontramos luego de la introducción una prolija y bien cuidada bibliografía que constituye una herramienta imprescindible para aquellos que se interesen en el pensamiento del nolano. No sólo contiene obras de Giordano Bruno y de otras fuentes tales como Plotino, Tomás de Aquino, Ficino, Pico, Agrippa, Spinoza y Schelling, entre otros; sino también una abundante literatura secundaria en idioma español, inglés, alemán, italiano y francés.

Al final de la edición encontramos un índice que se divide en, por un lado, un recuento de autores clásicos y figuras históricas que aparecen mencionados en el diálogo De la Causa, el principio y el uno; y, por otro lado, un recuento de autores, tanto clásicos como historiadores de la filosofía, que son citados tanto en la introducción de Granada como en las notas al pie del texto. Este formato resulta de mucha comodidad para su consulta y muy conveniente para encontrar referencias importantes en la edición en su totalidad. La edición carece, sin embargo, de un índice de conceptos.

Sólo resta destacar una vez más la notable erudición y el valioso aporte de Miguel Á. Granada a los estudios brunianos en idioma español. Este trabajo queda expuesto en la calidad de la traducción y cada nota al pie que explica, relaciona y discute importantes aspectos lingüísticos, históricos y filosóficos. En todo momento, Granada relaciona los conceptos brunianos con sus fuentes y sus proyecciones: advierte la posible presencia de Maimónides en Bruno como propuesta para una investigación más profunda; presenta el tratado De principiis naturae de Tomás de Aquino como fuente de la distinción que Bruno hace entre causa y principio; señala toda ocasión en la que puede advertirse influencia del De docta ignorantia y De possest del cusano, además de acercar al lector fragmentos traducidos en las notas al pie de Theologia platonica de Marsilio Ficino que Bruno tenía en consideración al escribir su obra, y un largo 
etcétera. Asimismo, se relacionan ideas presentes en el De la causa con otras obras del nolano, no sólo de su producción italiana, sino también de su opere latine (por ejemplo, De immenso et innumerabilibus, De minimo, Sigillus sigillorum, Cantus circaeus, etc.).
Todo ello hace de esta edición del De la causa, el principio y el uno una obra esencial para todo aquel que se interese por el pensamiento de Giordano Bruno y la filosofía de ese período maravilloso denominado Renacimiento. 